\title{
EL DEBILITAMIENTO DEL YO EN EL TARDOCAPITALISMO Y LA NUEVA PROPAGANDA FASCISTA*
}

\author{
The Weakening of the Ego in Late Capitalism and the New Fascist Propaganda \\ Jordi Magnet Colomer \\ Universitat Oberta de Catalunya \\ jordi.magnet@gmail.com
}

\begin{abstract}
Resumen:
El fermento psicológico del fascismo en las sociedades capitalistas tardías aparece vinculado al proceso de debilitamiento del yo y al necesario entrelazamiento de las disposiciones subjetivas con factores situacionales. Desentrañar los mecanismos que inciden en la expansión del carácter potencialmente fascista requiere de un análisis de las tendencias de la personalidad que favorecen su arraigo y cómo se ven fomentadas por determinados procesos sociales. El presente artículo se centra en el influjo y la interacción de tres factores objetivos y tres factores subjetivos. Para ello nos apoyamos principalmente en los estudios sobre la propaganda fascista y la cultura de masas llevados a cabo por los autores de la primera Teoría Crítica.
\end{abstract}

Palabras clave:

tardocapitalismo, Teoría Crítica, fascismo, extrema derecha, propaganda

\begin{abstract}
:
The psychological ferment of fascism in late capitalist societies appears linked to the process of weakening of the ego and the necessary interweaving of subjective dispositions with situational factors. Unravelling the mechanisms that influence the expansion of the potentially fascist character requires an analysis of personality tendencies that favor its acceptance and how they are fostered by certain social processes. This article focuses on the influence and interaction of three objective factors and three subjective factors. For this we rely mainly on studies on fascist propaganda and mass culture carried out by the authors of the first Critical Theory.
\end{abstract}

\section{Keywords:}

Late capitalism, Critical Theory, Fascism, Far Right, Propaganda

\footnotetext{
* Una primera versión de este texto en forma de ponencia fue presentada en el congreso "Historical Materialism", celebrado en la Nau Bostik de Barcelona los días 28, 29 y 30 de junio de 2019. Este trabajo ha sido realizado gracias al programa UNAM-PAPIIT IN402721 en el marco del grupo de investigación "Violencia, subjetividad y trauma colectivo".
} 
Recibido: 10/9/2020

Aceptado: $27 / 10 / 2020$

\section{CRISIS ECONÓMICA, INDUSTRIA CULTURAL Y COSIFICACIÓN DE LOS PROCESOS SOCIALES}

Entre los factores situacionales que fomentan el arraigo de las ideologías totalitarias y de su correspondiente mentalidad cabría mencionar en primer lugar las situaciones de crisis económica (1). Las épocas de crisis en las que amplios sectores de la población ven amenazada su seguridad económica y aflora el temor a un empobrecimiento material se convierten en contextos susceptibles de manipulación ideológica por parte de los partidos o grupos fascistas y de extrema derecha (Löwenthal y Guterman, 1949: 138). Tales movimientos prometen ciertas compensaciones que persuaden a determinados sectores de la población a aceptar la renuncia a las libertades alcanzadas a cambio de la promesa de mayor seguridad. Al estallar una crisis económica, la integración de los diversos estratos sociales en el principio de realidad dominante, junto al miedo a perder el nivel de vida logrado, condiciona la orientación de parte de la población hacia estas corrientes políticas.

El fascismo y la extrema derecha se nutren tanto de la decepción con la socialdemocracia como de las crisis provocadas por el capitalismo de laissez faire, especialmente en épocas de recesión económica donde las políticas sociales fracasan o no alcanzan a todos los segmentos necesitados, y ofrece en su lugar una particular rebelión contra el sistema. "Cuando la autonomía y la promesa de felicidad que ofrece la democracia no se cumple, se vuelven indiferentes a ella o pasan a odiarla secretamente" (Adorno, 2003: 65). El descontento derivado de la situación de crisis no se dirige al cuestionamiento de la "contradicción entre desigualdad económica e igualdad política formal, sino en contra de la forma democrática en cuanto tal" (Adorno, 2008: 385). Invocar a la democracia con objeto de confrontar sus creencias deviene inútil o contraproducente; para ellos 'democracia' es sinónimo de inseguridad y desempleo. La búsqueda de una mayor seguridad material sin la amenaza de expropiación de sus propiedades ahuyenta también la eventual apuesta por una transformación profunda del marco socioeconómico vigente, pues cualquier proceso en esta dirección despierta en ellos los fantasmas de la confiscación de la propiedad privada.

Al tratarse de una rebelión conformista contra el sistema, que deja intacta o refuerza la estructura socioeconómica generadora de tales inseguridades y desigualdades, "el pensamiento y acción de los seres humanos están en contradicción con la situación económica y, por tanto, son irracionales" (Reich, 1972: 32). Aunque su situación objetiva y las expectativas de mejorarla deberían conducirles a la adopción de posicionamientos políticos en sentido opuesto, su apuesta invierte esta supuesta racionalidad. La advertencia de Wilhelm Reich en los años treinta del pasado siglo continúa siendo válida a día de hoy: las explicaciones estrictamente socioeconómicas 
del fascismo y de la extrema derecha -que él atribuía entonces al marxismo vulgar y al economicismo- han demostrado su ineficacia. "Los preámbulos económicos a la revolución social se han verificado conforme a la teoría de Marx (...) Pero (...) la historia parece tomar, en la encrucijada de los caminos del socialismo y de la barbarie, primeramente la dirección de la barbarie" (Reich, 1972: 20).

De acuerdo con los postulados de la filosofía de la historia del marxismo tradicional, la agudización de las contradicciones del capitalismo en situaciones de crisis estructural ha de considerarse como la antesala del estallido de la revolución social. Sin embargo, la historia reciente ha desmentido en numerosas ocasiones dichas predicciones. Más bien, las crisis sistémicas del capitalismo -como la de 2008- han servido para alimentar a la extrema derecha (cfr. Romero, 2020: 87-88). En vista a ello, sin incorporar al análisis de la situación socioeconómica la consideración de ámbitos de mediación psicológica que permitan explicar el comportamiento irracional de los sujetos, los intentos de comprensión del fascismo y de la extrema derecha se revelan parciales e insuficientes $y$, en consecuencia, el camino regresivo hacia la barbarie resulta en gran medida indescifrable.

La reciente pandemia mundial generada a raíz de la expansión del virus del Covid19 ha puesto de manifiesto cómo las crisis sanitarias devienen una oportunidad tan propicia como los contextos de crisis económica para la difusión de discursos con contenido xenófobo y racista, dispuestos a transformarse en acción bajo la forma de ataques verbales o físicos indiscriminados. Estos discursos se enfocaron ya en un primer momento contra la comunidad asiática en general, a cuyos miembros se consideraba per se como seguros portadores de la enfermedad, y a los que se atribuía la responsabilidad de haber expandido el virus -y a menudo también de haberlo creado con fines de dominio- a nivel internacional. A medida que el contagio del virus avanzaba afectando a ciudades y regiones enteras en distintos países, la población residente en determinadas zonas, generalmente en los barrios más desfavorecidos con mayor porcentaje de población migrante o no blanca, con rentas más bajas y peores condiciones habitacionales que dificultaban las medidas de prevención del contagio, sufrieron también estigmatización y se les culpó igualmente de ser focos de transmisión de la enfermedad'. Si además se toma en consideración el hecho de que algunas de las profesiones más expuestas al contagio (trabajo de cuidados, recolección de fruta y verdura, etc.) son ejercidas en un alto porcentaje por personas migrantes, con o sin permiso de trabajo o residencia, para quienes el confinamiento y el teletrabajo no constituyen una opción ni una alternativa viables, se comprende fácilmente cómo el fascismo y la extrema derecha pueden sacar rédito de esta coyuntura y ofrecerse como medios para canalizar el miedo atizando el racismo contra ciertos grupos sociales. La pseudolegitimidad del discurso xenófobo no se logra en este caso responsabilizando a la población migrante o no blanca de sustraer el trabajo a

\footnotetext{
1 Sirva como testimonio de esta estigmatización los distintos bulos, acusaciones y ataques dirigidos contra las comunidades gitanas de Perpignan (Francia), Vitoria o Santoña (España). Sobre cómo el racismo, y el odio antigitano en particular, han hallado en la crisis sanitaria de la Covid-19 un medio idóneo para normalizarse y propagarse, véase, por ejemplo, Rromani Pativ (2020).
} 
los autóctonos, de acaparar las ayudas sociales o de ejercer las más variadas formas de delincuencia, sino de propagar una enfermedad capaz de poner en serio peligro la propia vida. La oportunidad que alberga un contexto de crisis sanitaria como el actual para el auge del fascismo y la extrema derecha consiste en que ahora el discurso del odio puede justificarse apelando a una causa de fuerza mayor, a la protección de la vida. La amenaza de enfermedad y de pérdida de la vida permite movilizar el racismo y la xenofobia con más éxito que la apelación a motivos económicos o relativos a la seguridad material. Las coartadas que suministra la crisis sanitaria para la difusión de la propaganda fascista convierten la defensa de su ideario en una cuestión de vida o muerte. Y cuando las consecuencias de una crisis sanitaria terminan confluyendo en una crisis económica, como parece ser el caso para la pandemia del Covid-19, se desencadena una dinámica de entrelazamiento y reforzamiento mutuo.

Otro proceso de carácter sistémico igualmente determinante -si bien, a diferencia del influjo de los contextos de crisis, exclusivamente característico del capitalismo tardío ${ }^{2}$ - es la transformación de la cultura en industria cultural (2), en un medio de entretenimiento y distracción en detrimento de su valor de uso (Zamora, 2007: 35). En el tardocapitalismo el individuo aparece cada vez más moldeado por las agencias de socialización de la cultura de masas. Por expresarlo con palabras de Marcuse, se ve arrastrado por el "flautista de Hamelin" de la industria cultural (Marcuse, 1970: 102). En este clima cultural estandarizado, donde se "glorifica el mundo tal como es" (Horkheimer, 2010: 153), los hábitos de pensamiento y las dinámicas de la personalidad reflejan también esta estandarización (Adorno, 2008: 340). Los sujetos reciben de las agencias de la cultura de masas patrones de pensamiento y de acción estandarizados y confeccionados "listos para su uso", "modelos de imitación colectiva" y de pensamiento estereotipado (Horkheimer, 2010: 162 y 166). En el capítulo XVII de los estudios sobre La personalidad autoritaria (1950), Adorno Ilamó la atención acerca del hecho de que este patrón ideológico global, este clima cultural

\footnotetext{
${ }^{2}$ En etapas previas o en los albores del capitalismo, así como en épocas precapitalistas, el odio antijudío también se manifestaba con mayor virulencia durante las épocas de crisis económica o sanitaria. Especialmente a lo largo de la Edad Media, los pogromos aumentaban en cantidad e intensidad cuando empeoraba la situación económica o sanitaria. La responsabilidad por las penosas circunstancias recaía a menudo en los judíos, quienes se convertían en los cabezas de turco ideales hacia donde poder descargar la ira acumulada. A título de ejemplo, las revueltas contra las comunidades judías acontecidas en diversas poblaciones de España en 1391 fueron justificadas por el vínculo que solía establecerse entre la epidemia de peste negra que azotaba Europa desde 1348 y la población judía. Bien se acusaba directamente a los judíos de propagar a conciencia la enfermedad -envenenando los pozos, etc.-, bien se interpretaba la epidemia como un castigo divino a los cristianos por convivir con la 'raza deicida', responsable de la muerte de Jesús. Pero las revueltas encontraron también pretextos en razones económicas. La prohibición expresa de ejercer determinados oficios en la 'esfera de la producción' relegó a los judíos a la 'esfera de la circulación', de modo que el negocio de préstamos representaba una de las pocas alternativas de las que disponían para poder sobrevivir. Pero ello generaba importantes recelos en el resto de la población, que les acusaba de enriquecerse a su costa, de obtener privilegios y protección de las autoridades con ganancias ilícitas y una comodidad material inalcanzable para los cristianos. Un detallado estudio sobre el odio tradicional a los judíos en las épocas precapitalistas, y sus similitudes y contrastes con el antisemitismo moderno, puede encontrarse en Claussen (1987).
} 
general, diluía y trascendía incluso la diferenciación psicológica entre puntuadores altos y bajos en la escala de medición de las actitudes y opiniones fascistas de los entrevistados (Adorno, 2008: 342-344), una tendencia global que no favorecía precisamente el cuestionamiento de tales orientaciones de la personalidad entre los sujetos de la muestra.

Podría decirse que la industria cultural promueve determinadas disposiciones subjetivas y una adaptación a lo existente por parte de los individuos -"asemejando su Yo-mismo al de los otros" (Marcuse, 1970: 104)- que allanan el terreno para la difusión y aceptación de la propaganda fascista. Con el proceso de uniformización de la personalidad según los estándares niveladores de la cultura de masas se aniquila también la individualidad que debiera servir de contrapeso para oponerse a las demandas de unificación en base a criterios nacionales, de etnia o de raza. La producción en serie de falsa conciencia por parte de la industria cultural le facilita las cosas al fascismo. El control social de la energía libidinal, mediante su desublimación represiva o comercial, incrementa también el nivel de maleabilidad de la economía pulsional de los sujetos para su eventual empleo o desublimación con fines políticos regresivos. La cultura de masas "secuestra hasta los últimos impulsos interiores de sus consumidores forzados" (Horkheimer y Adorno, 1998: 246).

El tercer y último factor objetivo con una incidencia no menos decisiva es la cosificación de los procesos sociales y el consecuente incremento de la alienación entre la esfera política y la esfera personal (3). Las complejidades de las sociedades contemporáneas generan incertidumbre y ansiedad entre la población. Y esta incertidumbre y ansiedad proporciona el caldo de cultivo para el florecimiento de movimientos reaccionarios populistas. Como la comprensión del "contexto de ofuscación" y de opacidad de la situación social y económica se encuentra obstaculizado, entre otros factores por la colonización de la conciencia operada por la industria cultural, y debido a que la comprensión de estas complejidades exige "un doloroso esfuerzo de conocimiento" (Adorno, 2003: 65) que uno no siempre está dispuesto a hacer o posee la capacidad para ello, fundamentalmente porque sustraerse al modo de pensar dominante mediante el pensamiento crítico exige "una gran fuerza psíquica" (Horkheimer, 2003: 121) y "produce ansiedad" (Adorno, 2008: 207), con frecuencia se recurre en su lugar a explicaciones simplistas. Se desarrollan técnicas de orientación rudimentarias para aliviar esta sensación de inseguridad y ansiedad, como el prejuicio y el estereotipo (cfr. Adorno, 2008: 352). Es decir, la cosificación y "opacidad de la actual situación política y económica para la persona promedio suministra una oportunidad ideal para la regresión al nivel infantil de estereotipo y personalización" (Adorno, 2008: 353). El individuo se aferra a patrones interpretativos y explicaciones simplistas de la realidad que empobrecen la experiencia antes que realizar el esfuerzo de penetrar intelectual y críticamente en la realidad.

El resentimiento resultante del proceso de alienación respecto a la esfera política o económica conduce a la necesidad de creación de chivos expiatorios en cuanto encarnaciones personalizadas de tendencias despersonalizadas que no se comprenden. Los representantes visibles de esas esferas devienen los chivos expiatorios por antonomasia: banqueros, especuladores financieros, élite empresarial, burócratas, clase política en general, etc. La construcción de una imaginería específica 
hacia donde poder dirigir el descontento mantiene la protesta en un nivel superficial. Supone además una regresión al estereotipo y al prejuicio y contribuye a desarrollar más si cabe los procesos psíquicos que la alientan. Pese a que con este procedimiento se logra evacuar parte del resentimiento acumulado, las tendencias sociales que causan malestar y sufrimiento siguen sin comprenderse. La satisfacción lograda mediante el ataque al blanco elegido es siempre incompleta y los sujetos conservan en su interior una considerable cantidad de resentimiento sobrante que puede emplearse en ulteriores proyecciones.

Paralelamente, como en el tardocapitalismo el sujeto apenas dispone de capacidad real para determinar su destino, el cual depende cada vez más de fuerzas autonomizadas y supraindividuales que escapan a su control, aumenta también la predisposición a desplazar la propia responsabilidad a fuerzas externas incontrolables. Junto al resentimiento y a la necesidad de creación de chivos expiatorios, la astrología y otras creencias supersticiosas pueden interpretarse como otra forma de reacción de los sujetos frente al extrañamiento, en última instancia como un signo de su claudicación o resignación y, por tanto, como síntoma de la debilidad del yo -proceso del que nos ocuparemos con más detenimiento en el siguiente apartado- ante las complejas e ininteligibles fuerzas objetivas que determinan su destino y parecen desarrollarse por encima de sus cabezas. La cosificación de los procesos sociales es tanto un prerrequisito para el surgimiento de diversos estereotipos contra determinados grupos sociales como un potente catalizador del pensamiento mágico y el misticismo.

\section{DEBILITAMIENTO DEL YO, AGRESIVIDAD SUBYACENTE Y NARCISISMO HERIDO}

Consideremos ahora los aspectos psicológicos que se encuentran entrelazados con los procesos de carácter objetivo esbozados, y con los que se retroalimenta. Debemos referirnos en primera instancia al proceso de 'debilitamiento del yo', a la pérdida de autonomía del individuo en la sociedad contemporánea (1). Dicho debilitamiento se traduce en la incapacidad de construir un sistema de valores autónomo y en la orientación hacia valores convencionales que disminuyen la capacidad de resistencia de los individuos frente a la presión social a la adaptación (Zamora, 2007: 40) (Adorno, 2003: 33). El sometimiento a la autoridad del padre en las sociedades capitalistas tradicionales deja paso en el capitalismo tardío al sometimiento a autoridades externas, a la autoridad del aparato de producción dominante (Marcuse, 1970: 104 y 107). Se produce así una sustitución del ideal del yo, de la construcción de una conciencia independiente y autónoma, por un superyó externo sádico y primitivo, por el convencionalismo y el autoritarismo. La autonomía del yo se reduce y este tiende a identificarse con el principio de realidad dominante. La precaria o inexistente internalización de estructuras superyoicas abstractas y despersonalizadas, así como el escaso desarrollo en la construcción de una autoridad interior en forma de conciencia, suponen una suerte de regresión a la situación vivida en la horda primitiva tal como la caracterizó Freud en Totem y tabú (1913), donde el sometimiento completo de los 
hijos al despotismo del todopoderoso padre primario les impedía desarrollar su propio yo y su ideal del $\mathrm{yo}^{3}$.

Con las transformaciones acaecidas en la estructura socioeconómica de las sociedades industriales desde el período de entreguerras (1918-1939) en adelante nos encontramos en un contexto paradójico, en lo que se ha venido a denominar sociedad sin padre (cfr. Mitscherlich, 1963). La imagen paterna y su autoridad en el seno de la familia patriarcal han sido reemplazadas por otras agencias del principio de realidad. Ahora la sociedad manipula y controla metódicamente dimensiones de la existencia antaño privadas y antisociales (Marcuse, 1970: 98), lleva a cabo una intensa expropiación psicológica en la que se administra instrumentalmente la economía instintiva de los sujetos (Horkheimer y Adorno, 1998: 246). Ciertamente, el decaimiento de la conciencia y la responsabilidad individuales posee también una causa objetiva justificada: ambas devienen superfluas para el funcionamiento autonomizado del capital. La progresiva mecanización del mundo dificulta su ejercicio o las vuelve irrelevantes. Asimismo, la decadencia del papel del padre en el capitalismo tardío marcha al unísono con el reemplazo del comercio minorista y la empresa privada y familiar por el gran monopolio, con el tránsito de la libre competencia a la competencia organizada y la subsiguiente "concentración del poder en las manos de una ubicua administración técnica, cultural y política" (Marcuse, 1970: 98) ${ }^{4}$. Cuanto más disminuye la capacidad de incidencia del padre en la esfera

\footnotetext{
${ }^{3}$ Conviene agregar en este punto que el ideal del yo también puede adoptar formas primitivas en las que se produce una fusión del concepto de sí mismo con un ideal grandioso del yo, esto es, con un concepto inflado de sí mismo donde el sí mismo real, el sí mismo ideal y el objeto ideal se confunden. El aumento desmesurado de carga libidinal en este sí mismo grandioso conduce a la negación de la dependencia de objetos externos y de representaciones internalizadas de estos. Sólo logran integrarse los componentes sádicos y primitivos del superyó y su diferenciación con el yo es deficiente (Kernberg, 1979: 208-209). Esta forma primitiva del ideal del yo sirve para compensar el debilitamiento del yo. No obstante, cabe entenderla como una estrategia de compensación de corto recorrido y escasa efectividad, puesto que las formas primitivas del ideal del yo se caracterizan también por una atrofia en el desarrollo yoico.

${ }^{4}$ Es sabido que los miembros de la primera Teoría Crítica llegaron a este diagnóstico asumiendo en lo fundamental las tesis defendidas por Friedrich Pollock en sus estudios sobre el capitalismo de estado y la economía planificada. Si bien en su época podía constatarse efectivamente una creciente intervención de los estados en la regulación de la economía y otras esferas centrales de la sociedad, reforzando sus funciones y su dominio con el recurso a formas de intervención más (nacionalsocialismo, bolchevismo) o menos (New Deal) autoritarias, en las últimas décadas ese poder ha menguado ostensiblemente en favor de la expansión de un libre mercado sin apenas controles estatales. Los estados se subordinan por completo a sus dinámicas y disponen de escasos medios en los casos -excepcionales- en que pretenden ejercer algún tipo de regulación sobre las mismas. Pero resulta evidente que este nuevo escenario no ha comportado ningún retorno al capitalismo liberal en su versión clásica ni a los modos de socialización que predominaban en él. Aunque puedan cuestionarse sus predicciones en relación al papel que confirieron al Estado en cuanto a su poder regulador de la economía, el diagnóstico sobre las restantes dinámicas epocales sí se ha visto confirmado -y acentuado- por el decurso histórico.
} 
económica, más se debilita su rol como representante del principio de realidad en el seno de la familia ${ }^{5}$.

La afectación de estas transformaciones de carácter socioeconómico en el proceso de debilitamiento del yo puede deducirse como sigue. La familia patriarcal no actúa ya como la principal agencia de socialización psíquica y la dinámica de la situación edípica ha dejado de ser el modelo que marca la pauta del hijo/a en ese proceso de socialización. Su entrada en el mundo social y laboral acontece con mayor independencia respecto al padre y la tradición familiar. "Las inevitables presiones y actitudes sociales ya no son aprendidas -e interiorizadas- en larga lucha con el padre" (Marcuse, 1970: 99). El yo del hijo/a aparece ahora como una entidad débil, entregada indefensamente al mundo sin haber consolidado suficientes herramientas de oposición, incapaz de construir un sí-mismo autónomo. A causa de la permisividad de la que ha disfrutado en el seno de una familia menos autoritaria, ese yo se ha desarrollado sin grandes luchas y otras agencias del principio de realidad, promotoras de conformismo y con más poder que el padre, han intervenido directamente en su socialización desde edades tempranas (Marcuse, 1970: 103). De este modo, desaparecen gran parte de las condiciones que podían ayudar a fortalecer la oposición de los individuos frente a la coacción social a la conformidad. La balanza entre autonomía y heteronomía se decanta en favor de la segunda ${ }^{6}$.

Frente a la capacidad de sublimación y de autocontrol del individuo autónomo (cfr. Resmann, 2017: 57), siguiendo a Otto Kernberg podemos enumerar los siguientes rasgos como manifestaciones características de debilidad yoica: intolerancia a la ansiedad, falta de control sobre los impulsos, insuficiente desarrollo de los canales de sublimación, ausencia de estructuras superyoicas integradas y su substitución por

${ }^{5}$ En relación con este proceso, en la sección general de la obra colectiva del Instituto de Investigación Social sobre Autoridad y familia (1936) Horkheimer señala, no obstante, que "la estructura de la autoridad en una familia dada puede ser lo suficientemente fuerte como para que el padre conserve su papel incluso cuando el fundamento material de este ha desaparecido (...)" (Horkheimer, 2003: 145).

${ }^{6}$ Resulta pertinente abrir un inciso para puntualizar a este respecto que el análisis de las consecuencias del proceso de socialización en las sociedades sin padre características del capitalismo post-liberal (debilidad yoica, desaparición de la autonomía y la individualidad) no debe entenderse en modo alguno como una suerte de nostalgia de los autores de la primera Teoría Crítica por las etapas precedentes del capitalismo, donde la familia patriarcal dirigida por el poder de un padre fuerte constituían todavía los principales ejes de socialización, y en la que en cierto modo se posibilitaba la construcción de una individualidad autónoma como resultado de la lucha de los hijos contra el principio de realidad encarnado en la autoridad paterna. Hay que tener en cuenta que estos modelos societarios, predominantes en el capitalismo liberal clásico, se sustentaban fundamentalmente en el dominio de la naturaleza externa, de una determinada clase social (burguesía) sobre otra (el proletariado), del hombre sobre la mujer, así como en una represión excedente, más allá de lo necesario para el aseguramiento racional de la reproducción social, de la energía libidinal de los sujetos, volviéndoles especialmente proclives a la neurosis. 
precursores superyoicos sádicos -no integrados- (Kernberg, 1979: 74, 81, 250, 251) ${ }^{7}$. A esta lista habría que añadir no sólo la tendencia del sujeto a desplazar la propia responsabilidad a fuerzas externas ajenas a su control, sobre la que ya hemos incidido, sino también la anti-intracepción (Adorno, 2008: 205) y la destrucción del recuerdo y la memoria (Adorno, 2003: 56).

El segundo factor de la personalidad funcional al carácter potencialmente fascista es la acumulación de agresividad subyacente que provoca en los individuos la internalización de las coacciones sociales, la rabia -aun inconsciente- de tener que someterse a los poderes existentes (2). El fascismo supone una vía de escape de estos impulsos agresivos y de esta rabia acumulada hacia determinados chivos expiatorios, generalmente hacia los más débiles en el eslabón social ${ }^{8}$. Se nutre de un malestar con la civilización y permite canalizar energías destructivas y escapar a la rigidez del autocontrol psicológico ${ }^{9}$.

En los extraños a la propia comunidad cultural se proyectan "los propios deseos reprimidos, las debilidades inaceptadas y los aspectos desagradables de sí mismo" (Zamora, 2003: 239). El mecanismo de la proyección consiste en la externalización de imágenes negativas del sí-mismo agresivo en los 'otros'. El ataque a los

\footnotetext{
${ }^{7}$ Götz Eisenberg y Reimer Gronemeyer se han ocupado de dilucidar las funestas consecuencias de la penetración de las dinámicas sociales y económicas del capitalismo tardío en instituciones centrales de la sociedad que antaño se mantenían en gran medida a resguardo de ellas, como es el caso de la familia, señalando los efectos altamente nocivos que tal fenómeno conlleva para el proceso de socialización en su conjunto y, en particular, para una correcta internalización del superyó en cuanto instancia capaz de contener la violencia y la agresividad de los individuos. Véase G. Eisenberg y R. Gronemeyer (1993: espec. 29-48).

${ }^{8}$ Adviértase la afinidad de este fenómeno con el resentimiento derivado de la cosificación de los procesos sociales al que nos hemos referido previamente. Por un parte, la alienación del contexto vital respecto a la esfera económica y política, cuyas complejidades el sujeto no alcanza a comprender, se traducen en un resentimiento en forma de prejuicios dirigidos contra las encarnaciones estereotipadas de sus representantes identificables. Por otra parte, en la necesidad de sumisión a los poderes fácticos -por tanto, no ya en la cosificación de los procesos sociales en cuanto tales- aflora también una agresividad que busca descargarse en otros chivos expiatorios, generalmente no hacia los poderosos, a quienes se debe respeto y obediencia, aunque sea bajo amenaza o imperativo legal, sino en los más débiles.
}

${ }^{9}$ De ahí la incitación que la propaganda fascista hace a menudo a "la liberación orgiástica de los propios instintos emocionales" (Adorno, 2008: 17). Sin embargo, esta libertad en la capacidad de expresión -física y verbal- suele reservarse en su grado más elevado únicamente a los líderes de tales movimientos, quienes, al contrario que su audiencia, sí pueden expresarse desinhibidamente. Rompen los tabúes establecidos y expresan públicamente lo que sus seguidores piensan en privado pero no se atreven a decir (Löwenthal y Guterman, 1949: 124). El dirigente o caudillo redime así su propia incapacidad de expresión (Adorno, 2003: 17). Las palabras de Adorno sobre Hitler pueden sacarse a colación cuando alguien muestra su estupefacción ante el hecho de que el electorado brinde su apoyo a candidatos visiblemente histriónicos: "Hitler no atraía a la gente a pesar de sus burdas bufonadas, sino precisamente a causa de ellas, gracias a sus falsos tonos y a sus payasadas" (Adorno: 2003: 16). 
representantes de la otredad es tanto más fanática "cuanto más se impone la experiencia de que uno es tan extraño a sí mismo como lo son los extraños" (Dahmer, 2006: 30). El resentimiento, la intolerancia y la frustración de las personas que engrosan las filas del fascismo y la extrema derecha se encauza primordialmente a denunciar la falta de frustración o de restricciones morales que perciben en los otros, corresponda o no este juicio con la realidad. Analizando algunos de los detonantes del antisemitismo en la sociedad estadounidense de posguerra, Adorno apuntaba a una suerte de sentimiento de envidia de aquellos plenamente socializados en la civilización americana, con su correspondiente atomización de la vida, frente al sentimiento de fraternidad, de calidez y la fortaleza de los vínculos sociales que parecían caracterizar las formas de vida de la comunidad judía (Adorno, 2008: 321). Por otra parte, el grado de tolerancia frente a los 'otros' extraños depende también de las condiciones sociales. "Bajo condiciones de paz, nivel de vida creciente y pleno empleo crece, bajo condiciones de crisis, cuando el miedo por la supervivencia domina a las personas, se reduce" (Dahmer, 2006: 28).

En este contexto, el psicoanálisis freudiano se convierte para la Teoría Crítica en "un aliado imprescindible para entender la génesis de la 'falsa conciencia' en la psique individual y las razones de la persistencia de una brutalidad 'arcaica' en el seno de una civilización supuestamente hipermoderna" (Maiso, 2013: 140). Cuando la precaria sublimación de la crueldad que sustenta la historia de la cultura humana fracasa, es decir, cuando resulta insuficiente para contenerla y la barbarie termina imponiéndose a la civilización, tienen lugar desublimaciones periódicas de la crueldad donde se desatan las energías destructivas acumuladas transgrediendo las barreras culturales prohibitorias. En ocasiones estas transgresiones, que pueden adoptar la forma de pogromos, limpiezas étnicas, guerras, etc., son alentadas por las mismas autoridades como una maniobra para desviar un descontento que de lo contrario podría volverse contra ellos poniendo en serio peligro la estabilidad y la reproducción de su dominio y sus privilegios. La renuncia a la satisfacción pulsional y a la agresividad vengativa para conservar el amor y la protección de la autoridad, cuyo origen ontogenético puede remontarse a la actitud de los hijos frente a sus padres, instituye un masoquismo primordial. Pero este autocastigo y el inmenso sacrificio que comporta la renuncia a la satisfacción pulsional exigida por la autoridad refuerzan también la protesta agresiva contra dicha privación, que a menudo adquiere tintes sádicos. La agresividad puede dirigirse hacia el interior en la forma de masoquismo o, en caso de que el sujeto no pueda -o quiera- retenerla, hacia el exterior en la forma de sadismo. En este sentido, Freud ya mostró la afinidad fundamental entre masoquismo y sadismo. A fin de cuentas, "el masoquismo es sin duda un sadismo vuelto hacia el yo propio" (Freud, 1975: 122).

El último aspecto subjetivo a resaltar es lo que algunos autores denominan 'narcisismo herido' $(3)^{10}$. Ante el sentimiento de impotencia y de insignificancia que los individuos experimentan en sus vidas, y que inflige continuamente heridas a su narcisismo, el fascismo les ofrece la posibilidad de un engrandecimiento narcisista del yo orientado hacia la omnipotencia (Zamora, 2007: 39). Aunque suponga una falsa

${ }^{10}$ Sobre el vínculo entre herida narcisista y agresividad, véase, por ejemplo, Fromm (2006: 205 210). 
curación de este narcisismo herido, mediante la elevación del narcisismo colectivo y nacional la propaganda fascista transforma "el sentimiento de la propia impotencia en un sentimiento de fuerza" (Adorno, 2008: 54). Al extraer amor propio de la supuesta grandeza de la nación, o del movimiento con el cual se identifica, satisface dichas pulsiones narcisistas. El repliegue patriótico, la exaltación de la 'madre patria', expresa el anhelo inconsciente de retorno a la seguridad del seno materno, en última instancia al estado de paz y tranquilidad de la vida intrauterina, frente a la inseguridad de la vida moderna encarnada en los enemigos de la patria. El recurso al narcisismo nacional como falsa sanación de la herida narcisista se vincula así con la regresión al estado -intrauterino- que mejor satisface el narcisismo originario del sujeto.

En el siguiente cuadro recogemos sintéticamente los puntos fundamentales esbozados hasta ahora en torno a la incidencia de los factores de carácter objetivo y subjetivo en la expansión del carácter potencialmente fascista y en el creciente apoyo a partidos y movimientos fascistas y de extrema derecha.

\begin{tabular}{|c|c|c|c|}
\hline Factores objetivos & Principales manifestaciones & Factores subjetivos & Principales manifestaciones \\
\hline (1) Crisis económica/sanitaria & $\begin{array}{l}\text { Temor a la pérdida de seguridad material } \\
\text { o vital. Reducción de la tolerancia hacia } \\
\text { los extraños a la propia comunidad cultu- } \\
\text { ral junto a su culpabilización por la situa- } \\
\text { ción de crisis }\end{array}$ & (1) Debilitamiento del yo & $\begin{array}{l}\text { Insuficiente desarrollo de los canales } \\
\text { de sublimación -impulsividad-. } \\
\text { Ausencia de estructuras superyoicas } \\
\text { integradas. Desplazamiento de la } \\
\text { responsabilidad individual a fuerzas } \\
\text { externas -pensamiento mágico, } \\
\text { misticismo-. Anti-intracepción. } \\
\text { Destrucción del recuerdo y la memo- } \\
\text { ria. Escasa autonomía e individuali- } \\
\text { dad. Menor capacidad de resistencia } \\
\text { frente a la presión social a la adap- } \\
\text { tación }\end{array}$ \\
\hline $\begin{array}{l}\text { (2) Transformación de la cultura } \\
\text { en industria cultural }\end{array}$ & $\begin{array}{l}\text { Adaptación a lo existente. Pensamien- } \\
\text { to y comportamiento estereotipados }\end{array}$ & $\begin{array}{l}\text { (2) Internalización de las coaccio- } \\
\text { nes sociales/obligación de some- } \\
\text { terse y obedecer a los poderes } \\
\text { existentes }\end{array}$ & $\begin{array}{l}\text { Resentimiento/agresividad dirigidos } \\
\text { contra chivos expiatorios }\end{array}$ \\
\hline $\begin{array}{l}\text { (3) Cosificación de los procesos } \\
\text { sociales }\end{array}$ & $\begin{array}{l}\text { Resentimiento/agresividad dirigidos con- } \\
\text { tra chivos expiatorios. Tendencia a la su- } \\
\text { perstición y a desplazar la propia respon- } \\
\text { sabilidad a fuerzas externas }\end{array}$ & (3) Narcisismo herido & $\begin{array}{l}\text { Necesidad de identificación con } \\
\text { partidos o movimientos nacionalistas } \\
\text { que reparen esta herida. } \\
\text { Tránsito del sentimiento de impoten- } \\
\text { cia a un sentimiento de omnipoten- } \\
\text { cia }\end{array}$ \\
\hline
\end{tabular}

El factor objetivo 2 (Transformación de la cultura en industria cultural) contribuye a potenciar el factor subjetivo 1 (Debilitamiento del yo). Asimismo, como ya hemos señalado, existe una estrecha vinculación entre las manifestaciones características del factor objetivo 3 (Cosificación de los procesos sociales) y las del factor subjetivo 2 (Internalización de las coacciones sociales/obligación de someterse y obedecer a los poderes existentes). Hemos subrayado también cómo en situaciones de crisis (factor objetivo 1) disminuye la tolerancia frente a los 'otros', incrementando así la agresividad dirigida contra ellos, principal manifestación del factor subjetivo 2 (Internalización de las coacciones sociales/obligación de someterse y obedecer a los poderes existentes). 
Por otra parte, a mayor grado de desarrollo del factor subjetivo 1 (Debilitamiento del yo), mayor predisposición y virulencia en las principales manifestaciones de los factores subjetivos 2 (Internalización de las coacciones sociales/obligación de someterse y obedecer a los poderes existentes), 3 (Narcisismo herido) y del factor objetivo 3 (Cosificación de los procesos sociales). Cabe considerar el proceso de debilitamiento del yo, intensificado por los patrones de socialización de la industria cultural, como un factor transversal que promueve y potencia las manifestaciones principales de gran parte de los factores restantes.

\section{CARACTERÍSTICAS GENERALES DE LA NUEVA PROPAGANDA FASCISTA}

Junto al control y a la manipulación de procesos en gran parte irracionales e inconscientes, así como a su función como medio para canalizar energías destructivas y para reparar falsamente el narcisismo herido, la propaganda fascista tiene por lo general un carácter no teórico. Explota un estado de descontento sin hacer explícito ese descontento con conceptos racionales (Löwenthal y Guterman, 1949: 6). No hace responsable a la estructura social existente de los males sociales, no remite la insatisfacción social a causas claramente definidas e identificables. Se trata de una insatisfacción sin correlato objetivo. La naturaleza no teórica de la propaganda fascista se halla en consonancia con el desvío del pensamiento discursivo apreciable en sus receptores, donde a menudo los juicios de valor afectivos se imponen a la fuerza de los argumentos (Reich, 1972: 105).

Tal propaganda suele referirse de manera recurrente a sus enemigos usando la estratagema del "coco del comunismo", de la amenaza roja. En la propaganda fascista se percibe la tendencia a "atacar espectros más que a opositores reales" (Adorno, 2003: 14), a construir y atacar una imagen del enemigo más que a la realidad o amenaza que pudieran representar (Adorno, 2008: 120). Esta imagen del enemigo se convierte, según Adorno, en "receptáculo para toda clase de proyecciones hostiles", que no son otra cosa "que reminiscencias (...) a un nivel infantil de la presentación de las fuerzas del mal en tiras de cómic", películas o series de televisión (Adorno, 2008: 438 $)^{11}$. En el capitalismo tardío se constata, pues, una perfecta adaptación de la propaganda fascista a la industria cultural del entretenimiento ${ }^{12}$. El fascismo y su propaganda se han vuelto espectaculares. Y cuanto más espectacular tiende a volverse el fascismo, más se inclina la sociedad del espectáculo hacia el fascismo. Es por esta razón que podemos hacer uso, sin temor a exagerar, de la palabra "propaganda", en el sentido publicitario del término. No por casualidad Adorno llegó a caracterizar el antisemitismo como una "ontología de la publicidad" (Adorno, 2003: 77).

Por lo demás, en una época caracterizada por la centralización y manipulación de los medios de comunicación oficiales, los agitadores o políticos populistas fascistas y de extrema derecha acostumbran a presentarse como lobos solitarios para demostrar que sus opiniones son sinceras y no dependen de terceros ni de ninguna poderosa agencia de comunicación. A su juicio, los medios de información pública y la cultura

\footnotetext{
${ }^{11}$ Sobre esto véanse las imágenes 1 y 2 adjuntadas en el Anexo.

${ }^{12}$ Cfr. imágenes 3 y 4 del Anexo.
} 
oficial se hallarían en manos de los enemigos de la nación. "Los propagandistas se aprovechan de la desconfianza pública respecto a la manipulación en los poderes actuales dentro de los medios de comunicación y los partidos políticos" (Adorno, 2008: 15). Por este motivo, en la actualidad prefieren difundir su ideología a través de otros medios menos oficiales, como las redes sociales. Sin embargo, a menudo sus opiniones son también vetadas por los administradores de estos canales, especialmente cuando aprovechan las plataformas digitales para difundir noticias falsas o vejatorias con vistas a favorecer sus intereses o a expandir su peculiar concepción del mundo y las supuestas amenazas que se ciernen sobre él.

Su particular cruzada es contra lo que denominan "marxismo cultural", que no consiste sino en una reactualización -surgida en los años ochenta y noventa del pasado siglo en el ámbito de la extrema derecha norteamericana- de la teoría de la conspiración judeo-masónica. Si bien en el ámbito público y en la esfera política oficial esta lucha no adquiere rasgos tan explícitos ni disparatados como en épocas precedentes, en las redes sociales continúa dándose rienda suelta a la imaginación con estrategias análogas a las empleadas en la teoría de la conspiración judeomasónica clásica ${ }^{13}$. En los medios donde se impone la corrección política y cierta moderación en el discurso, la actualización de la teoría de la conspiración judeomasónica adopta formas más sutiles, aunque apenas disimulables. Tómese como ejemplo las constantes invectivas dirigidas a la figura del 'magnate húngaro de origen judío' -así es como suelen presentarle los medios de comunicación de todas las tendencias- George Soros, no sólo en su país natal por parte de Viktor Orbán y afines, sino también más allá de sus fronteras ${ }^{14}$.

La teoría de la conspiración, la creencia en fuerzas ocultas que controlan desde la sombra el destino del mundo, constituye una de las formas de expresión distintivas del criptofascismo y del criptoantisemitismo. El recurso paranoide a la conspiración es especialmente propenso al uso de la insinuación y a la difusión de rumores.

El cuchicheo, el rumor (alguna vez he dicho que el antisemitismo es el rumor sobre los judíos), la opinión que no acaba de decirse a las claras, son desde siempre el medio en el que se mueven los descontentos sociales de todo tipo y que, dentro del orden social, no osan salir a la luz. Quien se dedica de tal modo a la opinión, al rumor, actúa de entrada como si perteneciese a una comunidad verdadera, oculta y oprimida por las formas

\footnotetext{
${ }^{13}$ Cfr. imágenes 5, 6, 7 y 8 del Anexo.

${ }^{14}$ A principios del mes de noviembre de 2019, Javier Ortega Smith, secretario general del partido español de ultraderecha Vox, insinuó que Soros estaba detrás y había financiado (ejerciendo una especie de poder oculto), el manifiesto suscrito por quinientos científicos sociales en el que se acusaba a Vox de falsear datos sobre cuestiones vinculadas con la inmigración o la violencia de género. Sus palabras textuales fueron las siguientes: "Ya sabemos que Soros tiene mucho poder económico y es capaz de pagar un informe de mil quinientos expertos o de cinco mil, da lo mismo". En el marco de una tertulia televisiva celebrada el 13 de enero de 2020, Santiago Abascal, líder de esta formación política, calificaba a Soros de "personaje siniestro".
} 
superficiales de la sociedad (Adorno, 2003: 73-74).

Puesto que con posterioridad a la segunda guerra mundial las leyes instauradas en numerosos estados prohíben las declaraciones abiertamente racistas y/o antisemitas, con el fin de propagar con mayor disimulo sus tesis acerca del control y la influencia perniciosa ejercida a nivel mundial por sus enemigos, sean estos magnates judíos, inmigrantes o el marxismo cultural, el fascismo y la extrema derecha se ven obligados a recurrir a menudo a procedimientos velados ${ }^{15}$. Pero de este modo surge una "simpatía con la opinión no pública" que alberga un potencial más peligroso que el discurso sincero y abierto (Adorno, 2003: 89), pues recluta, por así decirlo, un ejército de reserva subterráneo siempre al acecho, preparado para salir a la superficie y tomar el control de la esfera pública tan pronto como la correlación de fuerzas se lo permita.

Otra de las características comunes al fascismo y al antisemitismo modernos es la flexibilidad retórica. Con ella los líderes fascistas y de extrema derecha, así como sus simpatizantes, pueden sortear hábilmente el esperable efecto de repulsa que produciría en una parte todavía significativa de la opinión pública las manifestaciones francas de sus ideas e intenciones, aun cuando en ocasiones el rechazo a estas manifestaciones no venga motivado tanto por el hecho de que suelen atentar contra los principios más fundamentales de la dignidad humana, sino porque transgreden efectivamente el discurso de la corrección política dominante en las democracias occidentales desde 1945. Aunque con el uso de la flexibilidad retórica incurran con frecuencia en contradicciones flagrantes, les permite no obstante reparar errores estratégicos cometidos, adaptarse mejor a las fluctuaciones de los temas de actualidad y a las corrientes mayoritarias de opinión. El estilo camaleónico de su discurso sirve también para ampliar el espectro de apoyos entre el potencial electorado. Así, según estimen oportuno por mero tacticismo, las declaraciones públicas de sus dirigentes, y el modo de funcionamiento interno y externo de los partidos o movimientos que les ofrecen cobijo, se mostrarán como más o menos democráticos, como más o menos o radicales. Ambas tendencias pueden coexistir sincrónicamente o sin apenas lapsos temporales entre ellas. Cuando esta flexibilidad alcanza su punto límite tiene lugar una auténtica inversión. En estos casos, por ejemplo, aparentarán ser unos fervientes

\footnotetext{
${ }^{15}$ Esto no significa que no existan diferencias significativas en la legislación entre estados. En aquellos países -sobre todo Alemania- donde la expresión de tales ideas está más perseguida por la ley, el criptofascismo y el criptoantisemitismo son más pronunciados y, en consecuencia, mayor es la amenaza que representan. Por el contrario, en otros países como España, donde la legislación al respecto es más laxa, donde se permite operar con cierta normalidad a partidos y fundaciones de carácter abiertamente fascista, las oportunidades de manifestar públicamente tal ideología son mayores y, por tanto, menor es la incidencia del criptofascismo y el criptoantisemitismo. Pero en uno y otro caso, la opinión pública, cimentada en el respeto general por la democracia inculcado a los ciudadanos, encuentra su reverso en la creación de una opinión no pública antidemocrática, tendencia al alza cuando las democracias hacen aguas. Una fórmula alternativa, compatible con la existencia de un criptofascismo soterrado, consiste en servirse de la democracia (esto es, en acatar lo establecido en las respectivas constituciones, renunciar al uso de la violencia explícita, participar en las elecciones, etc. En definitiva, en aceptar, al menos en apariencia, las reglas del juego democrático) para erosionarla gradualmente $y$, llegado el momento oportuno, destruirla.
} 
detractores del antisemitismo, presentándose a sí mismos como los "verdaderos amigos de los judíos" o "manifestando sentimientos abiertamente pro-judíos" (Rensmann, 2017: 341). Basta, empero, un análisis mínimamente atento de su trayectoria, para desvelar su verdadera naturaleza antisemita ${ }^{16}$. Resulta ineludible remitirse a la investigación del Group Experiment que el Instituto de Investigación Social llevó a cabo en 1955 en Alemania (cfr. Pollock y Adorno, 2011) para comprender en toda su dimensión y complejidad las dinámicas psicológicas latentes que operan en el antisemitismo secundario -concepto introducido por Adorno y Peter Schönbach en los años cincuenta- y la consecuente persistencia de opiniones de carácter fascista, que no emergen inicialmente a la superficie, en los estados formalmente democráticos. Una meritoria actualización de los análisis de la primera Teoría Crítica en esta dirección, aplicados a las sociedades contemporáneas específicamente al caso de Alemania, pero extensibles a otros países- son los MitteStudien coordinados por Oliver Decker ${ }^{17}$.

Para contrarrestar el efecto y el arraigo de la propaganda fascista en las sociedades capitalistas tardías es preciso analizar las diversas tendencias objetivas y subjetivas que lo promueven e intentar revertirlas en la medida de lo posible. Gran parte de su efectividad radica en el hecho de que las estrategias que emplea para difundir su ideario están perfectamente amoldadas a la industria cultural y, por tanto, son susceptibles de enraizar en aquellos sujetos cuyas personalidades han sido más conformadas por tal industria, por los patrones estandarizados de pensamiento y comportamiento que ofrece. Tal vez aquí resida una de las principales razones de la atracción que estos partidos y movimientos parecen ejercer entre la llamada generación Millennial. Aspirar a fortalecer el yo autónomo y la individualidad, pese a todas las tendencias objetivas y a los modos de subjetivación y socialización predominantes en el capitalismo post-liberal que actúan en sentido inverso, implica rechazar de suyo la tesis de un dominio consumado de la naturaleza interna sin escapatoria para el sujeto. Las fuentes de resistencia frente al fascismo y la extrema derecha han de buscarse todavía en las "fuerzas procedentes de ese estrato en que el principium individuationis, mediante el que se impuso la civilización, se afirma aún

\footnotetext{
${ }^{16}$ Podemos recurrir nuevamente al caso paradigmático de Vox, pues escasos meses antes de las citadas declaraciones de Ortega Smith y Abascal sobre Soros, el partido forzó la dimisión del cabeza de lista de la formación en Albacete, el pseudohistoriador Fernando Paz, por la difusión de unas declaraciones suyas, pronunciadas en 2016 como ponente invitado en una conferencia organizada en la sede de la Falange, donde defendía postulados revisionistas y negacionistas del Holocausto. Que se trata de una operación de limpieza interna de cara a la galería lo prueba el hecho de que paralelamente sus dirigentes se erijan como uno de los máximos voceros de las tesis de la teoría de la conspiración del marxismo cultural, cuyas analogías con la teoría de la conspiración judeo-masónica resultan evidentes, tal como las invectivas a Soros han sacado a la luz de manera palmaria. Tampoco las periódicas felicitaciones en las cuentas de Twitter de Vox a la comunidad judía por sus festividades son suficientes para compensarlo u ocultarlo.

${ }^{17}$ Una reseña de los resultados obtenidos por las investigaciones teórico-empíricas de Oliver Decker y su equipo en los distintos volúmenes publicados hasta la fecha puede encontrarse en Zamora (2018). Véase también la conversación de Decker con Christoph Türcke (2018) aparecida en el mismo número de Constelaciones. Revista de Teoría Crítica.
} 
contra el proceso de civilización que lo liquida" (Adorno, 2004: 85). La esperanza en una actitud no conformista del sujeto, capaz de oponerse a estas corrientes regresivas, anida, como señaló Claussen (1988: 25), en la "ausencia de simultaneidad entre objetividad social y subjetividad individual", en "la no identidad entre estructura psíquica y social".

ANEXO

imagen 1

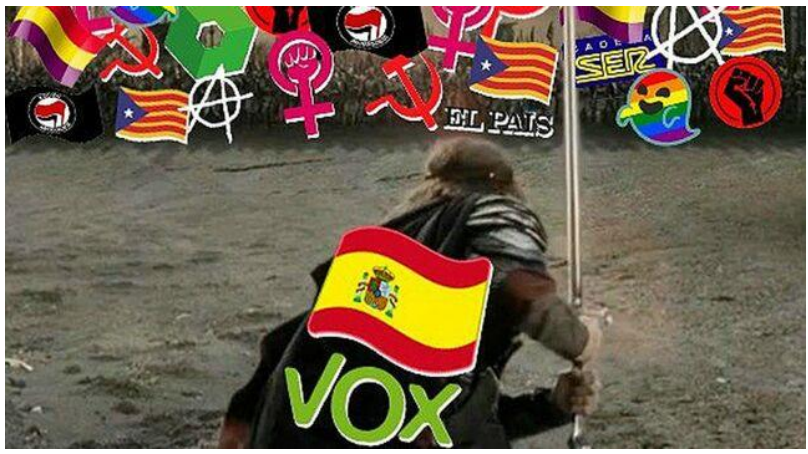

Este fotomontaje, elaborado a partir de la imagen de una secuencia de la película "El señor de los anillos", fue empleado por el partido político español Vox en la campaña de las elecciones generales de abril de 2019. Es ciertamente ilustrativa de esas proyecciones hostiles del enemigo basadas "en reminiscencias a un nivel infantil de la presentación de las fuerzas del mal", tal como aparecen representadas en distintos productos gráficos de la industria cultural. Un segundo rasgo apreciable, que comparte con otros partidos, movimientos y sujetos afines, es la no distinción entre tales "fuerzas del mal", sean estas reformistas o revolucionarias, medios de comunicación, movimientos sociales o nacionalistas -de signo opuesto-, entre otros. (cfr. Löwenthal y Guterman, 1949: 39). Sugiere también que el peligro de catástrofe es inminente, que la temida revolución puede suceder en cualquier momento si uno no está permanentemente alerta y dedica todas sus fuerzas a combatirla. imagen 2

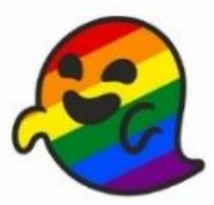

Que la tendencia a "atacar espectros más que a opositores reales", a construir y atacar una imagen del enemigo más que a la realidad o amenaza que pudieran representar, no es en modo alguno una exageración del análisis de la propaganda fascista, lo demuestra esta imagen extraída del anterior fotomontaje. El fantasma, bautizado popularmente con el nombre de 'Gaysper', simboliza la amenaza del movimiento LGTBIQ+. La posibilidad que probablemente no contemplaban los responsables de comunicación del partido que difundieron el fotomontaje en las redes sociales, es que el fantasma en cuestión acabaría convirtiéndose en una suerte de emblema de la comunidad gay.

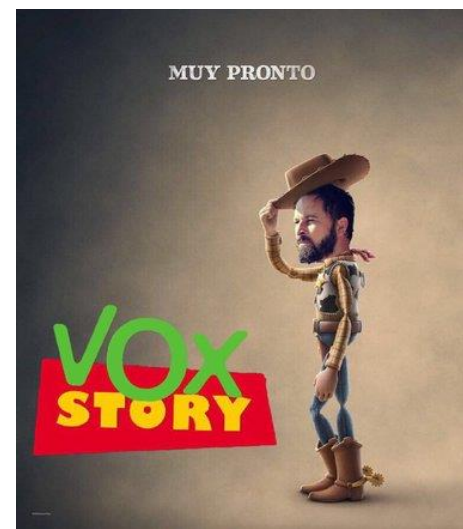

imagen 3

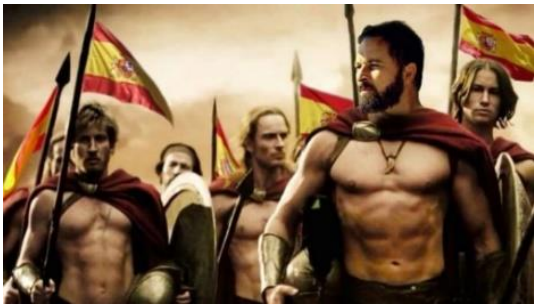

imagen 4
En contra de lo que podría suponerse, ambos 'memes', fotomontajes de las películas "Toy Story" y "300" donde se ha insertado el retrato del dirigente de la formación política en lugar de la de sus protagonistas reales, no fueron creados ni difundidos por activistas digitales opositores a la formación política, sino desde las filas del propio partido en su estrategia por aproximarse a las nuevas generaciones, aparentemente más influenciables por estas formas de propaganda. 
imagen 5

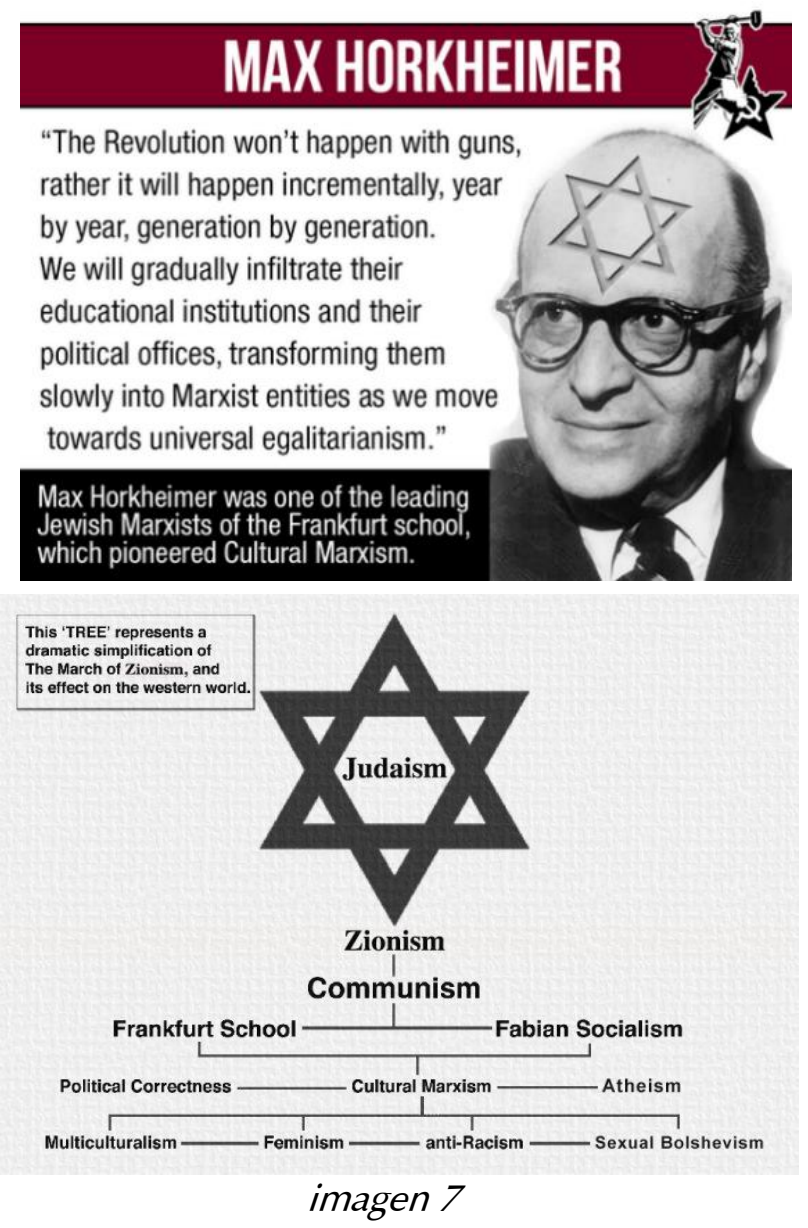

imagen 6

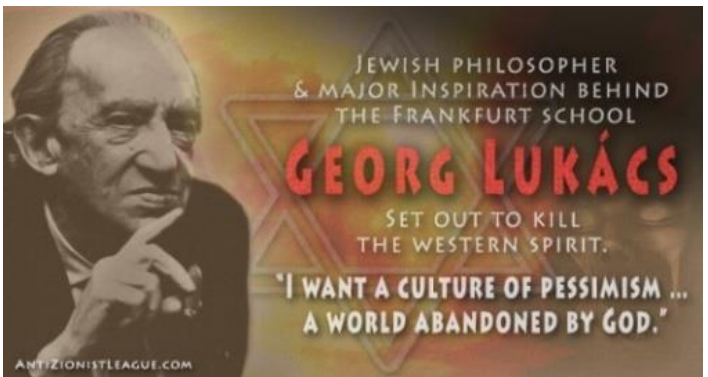

Aun cuando Horkheimer y Lukács no pronunciasen jamás las palabras que se les atribuyen en las citas, lo que interesa en la teoría de la conspiración del marxismo cultural es presentar a los intelectuales judíos -la Escuela de Frankfurt y sus influencias-, como los máximos precursores y promotores de la destrucción (operada desde la sombra, infiltrándose sigilosamente) de los valores de la civilización occidental. Tal como figura en el 'árbol' de la imagen 7, la línea genealógica se iniciaría con el judaísmo y culminaría en el multiculturalismo, el feminismo, el antiracismo y el bolchevismo sexual, pasando por la Escuela de Frankfurt, el marxismo cultural o la corrección política.

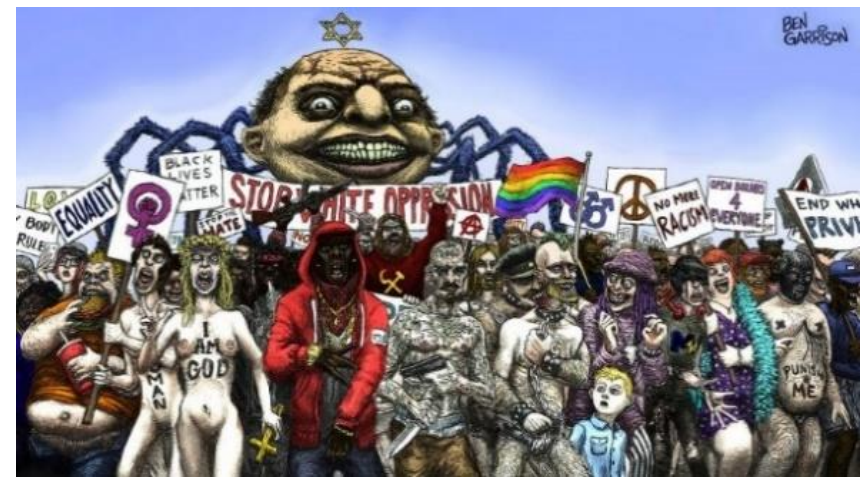

imagen 8

El dibujante Ben Garrison condensa en la última imagen dos recursos habituales en los medios antisemitas. Por una parte, puede verse una enorme 'araña judía' guiando lo que pretende ser una 'marcha de la degeneración'. Caracterizar al enemigo como un pequeño insecto o roedor repulsivo y peligroso, que se reproduce en ambientes sucios y que, por tanto, debe eliminarse sin miramientos -para evitar la extensión de plagas, etc-, es una estrategia reiterada en la propaganda fascista (Löwenthal y Guterman, 1949: 55-58). Por otro lado, "la idea de regeneración con la implicación del odio hacia los degenerados es común a todos los antisemitas" (Adorno, 2008:41). 


\section{BIBLIOGRAFÍA}

Adorno, Th. W. (2003). Ensayos sobre la propaganda fascista. Psicoanálisis del antisemitismo. Barcelona: Voces y culturas

Adorno, Th. W. (2004). Escritos sociológicos I. Madrid: Akal.

Adorno, Th. W. (2008). Escritos sociológicos II, vol. 1. La técnica psicológica de las alocuciones radiofónicas de Martin Luther Thomas. Estudios sobre la personalidad autoritaria. Madrid: Akal.

Adorno, Th. W. (2011). Escritos sociológicos II, vol. 2. Bajo el signo de los astros. Culpa y represión. Madrid: Akal.

Claussen, D. (1987). Vom Judenhaß zum Antisemitismus. Materialien einer verleugneten Geschichte. Darmstadt und Neuwied: Luchterhand.

Claussen, D. (1988). Unterm Konformitätszwang. Zum Verhältnis von Kritischer Theorie und Psychoanalyse. Bremen: Wassmann.

Dahmer, H. (2006). La sociología al final de un siglo de barbarie. Lima: Fundación Friedrich Ebert.

Eisenberg, G. y Gronemeyer, R. (1993). Jugend un Gewalt. Der neue Generationenkonflikt oder Der Zerfall der zivilen Gesellschaft. Reinbek: Rowohlt.

Freud, S. (1975). "Pulsiones y destinos de pulsión", en: Obras completas XIV. Buenos Aires: Amorrortu.

Fromm, E. (2006). Anatomía de la destructividad humana. México: Siglo XXI.

Horkheimer, M. (2003). "Autoridad y familia", en: Teoría crítica. Buenos Aires: Amorrortu.

Horkheimer, M. (2010). "Ascenso y ocaso del individuo", en: Crítica de la razón instrumental. Madrid: Trotta.

Horkheimer, M. y Adorno, Th. W. (1998). Dialéctica de la Ilustración. Fragmentos filosóficos. Madrid: Trotta.

Kernberg, O. (1979). Desórdenes fronterizos y narcisismo patológico. Barcelona: Paidós.

Löwenthal, L. y Guterman, N. (1949). Prophets of Deceit. A Study of the Techniques of the American Agitator. New York: Harper and Brothers. 
Maiso, J. (2013). "La subjetividad dañada: Teoría Crítica y psicoanálisis", Constelaciones. Revista de Teoría Crítica, número 5 (diciembre 2013), pp. 132-150.

Marcuse, H. (1970). "El anticuamiento del psicoanálisis", en: Ética de la revolución. Madrid: Taurus.

Mitscherlich, A. (1963). Auf dem Weg zur Vaterlosen Gesellschaft. Ideen zur Sozial Psychologie. Munich: R. Piper \& Co. Verlag.

Pativ, R. (2020). "El Covid-19 y el virus del racismo", CTXT. Contexto y acción (12/03/2020).

Pollock, F. y Adorno, Th. W. (2011). Group Experiment and Other Writings. The Frankfurt School on Public Opinion in Postwar Germany. Cambridge: Harvard University Press.

Reich, W. (1972). Psicología de masas del fascismo. Madrid: Ayuso.

Rensmann, L. (2017). The Politics of Unreason: The Frankfurt School and the Origins of Modern Antisemitism. Albany: SUNY Press.

Romero, J. M. (2020). "El socialismo como crítica inmanente del capitalismo. Una discusión con Axel Honneth", en: Romero, J. M. y Zamora, J. A. (eds.). Crítica inmanente de la sociedad. Barcelona: Anthropos, pp. 85-106.

Türcke, C. y Decker, O. (2018). "El centro-Un lugar mítico. Oliver Decker en conversación con Christoph Türcke", Constelaciones. Revista de Teoría Crítica, no 10, pp. 394-410.

Zamora, J. A. (2003). "Th. W. Adorno y la aniquilación del individuo", Isegoría: revista de filosofía moral y política, no 28, pp. 231-240.

Zamora, J. A. (2007). "El enigma de la docilidad. Teoría de la sociedad y psicoanálisis en Th. W. Adorno", en: Cabot, M. (ed.): El pensamiento de Th. W. Adorno. Balance y perspectivas. Palma: Universitat de les Illes Balears, pp. 27-42.

Zamora, J. A. (2018). "Oliver Decker et. al.: Mitte-Studien (2006-2018, 8 vols.)", Constelaciones. Revista de Teoría Crítica, no 10, pp. 512-519.

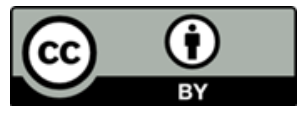

